\title{
The prevalence and increasing trends of overweight, general obesity, and abdominal obesity among Chinese adults: a repeated cross-sectional study
}

\author{
Yongjie Chen, Qin Peng, Yu Yang, Senshuang Zheng, Yuan Wang and Wenli Lu*
}

\begin{abstract}
Background: The prevalence of general and abdominal obesity has increased rapidly in China. The aims of this study were to estimate the dynamic prevalence of overweight, general obesity, and abdominal obesity and the distribution of body mass index (BMI) and waist circumference (WC) among Chinese adults.
\end{abstract}

Methods: Data were obtained from the China Health and Nutrition Survey (CHNS). According to the suggestions of the WHO for Chinese populations, overweight was defined as a $23 \mathrm{~kg} / \mathrm{m}^{2} \leq \mathrm{BMl}<27.5 \mathrm{~kg} / \mathrm{m}^{2}$ and general obesity as a $B M I \geq 27.5 \mathrm{~kg} / \mathrm{m}^{2}$. Abdominal obesity was defined as a $W C \geq 90 \mathrm{~cm}$ for males and $\geq 80 \mathrm{~cm}$ for females. Grade 1 , grade 2, and grade 3 obesity were defined as $27.5 \mathrm{~kg} / \mathrm{m}^{2} \leq \mathrm{BMl}<32.5 \mathrm{~kg} / \mathrm{m}^{2}, 32.5 \mathrm{~kg} / \mathrm{m}^{2} \leq \mathrm{BMl}<37.5 \mathrm{~kg} / \mathrm{m}^{2}$, and $\mathrm{BMI} \geq 37.5 \mathrm{~kg} / \mathrm{m}^{2}$, respectively. Generalized estimation equations were used to estimate the prevalence and trends of overweight, general and abdominal obesity.

Results: This study included 12,543 participant. From 1989 to 2011, the median BMI of males and females increased by $2.65 \mathrm{~kg} / \mathrm{m}^{2}$ and $1.90 \mathrm{~kg} / \mathrm{m}^{2}$, respectively; and $W C$ increased by $8.50 \mathrm{~cm}$ and $7.00 \mathrm{~cm}$, respectively. In 2011 , the age-adjusted prevalence of overweight, general obesity, and abdominal obesity were 38.80\% (95\% Cl: $37.95-$ 39.65\%), 13.99\% (95\% Cl: 13.38-14.59\%), and 43.15\% (95\% Cl: 42.28-44.01\%), respectively, and significantly increased across all cycles of the survey among all subgroups (all $P<0.0001$ ). The age-adjusted prevalence of grade $1-3$ obesity significantly increased in total sample and sex subgroups (all $P<0.0001$ ). For all indicators, there were significant increases in annual ORs among all subgroups (all $P<0.0001$ ), with the exception of grade 2 obesity. Significant differences were observed in ORs across the three age groups in males. And ORs significantly decreased with age.

Conclusions: The age-adjusted prevalence of overweight, general obesity, and abdominal obesity significantly increased among Chinese adults from 1989 to 2011. The obesity population is trending toward an increased proportion of males and younger individuals in China.

Keywords: Body mass index, Waist circumference, General obesity, Abdominal obesity

\footnotetext{
* Correspondence: luwenli@tmu.edu.cn

Department of Epidemiology and Statistics, School of Public Health, Tianjin

Medical University, 22 Qixiangtai Road, Tianjin, China
}

(c) The Author(s). 2019 Open Access This article is distributed under the terms of the Creative Commons Attribution 4.0 International License (http://creativecommons.org/licenses/by/4.0/) which permits unrestricted use, distribution, and reproduction in any medium, provided you give appropriate credit to the original author(s) and the source, provide a link to the Creative Commons license, and indicate if changes were made. The Creative Commons Public Domain Dedication waiver (http://creativecommons.org/publicdomain/zero/1.0/) applies to the data made available in this article, unless otherwise stated. 


\section{Background}

Overweight and obesity are important lifestyle-related public health problems worldwide $[1,2]$. Since obesity is associated with the common chronic diseases, including cardiovascular disease, type 2 diabetes, hypertension, dyslipidemia, and certain types of cancer, and considered as the fifth leading risk factors for mortality globally [2-8], obesity-related issues have drawn more and more attention from researchers in recent decades. Therefore, it is necessary to investigate and monitor the trends in the prevalence of overweight and obesity to improve awareness and make preventive strategies in the public health field.

In recent years, the prevalence of overweight and obesity has reached epidemic proportions in China $[9,10]$. Approximately $20 \%$ obesity individuals worldwide are Chinese [11]. The considerable increase in the prevalence of obesity is attributed to the adoption of a Western lifestyle and decreased physical activity [12]. The traditional Chinese diet, characterized by a high carbohydrate content composed of rice, wheat, and cooked vegetables, is shifting to a diet with higher fat $[13,14]$. The high intake of energy and fat combined with a decrease in physical activity are responsible for the increasing prevalence of overweight and obesity in the Chinese population, especially among urban inhabitants $[15,16]$. Depicting the trends in the prevalence of obesity will help elucidate the prevalence of obesityrelated chronic diseases and alert health care professionals and the public to prevent the epidemic.

Body mass index (BMI) is a common indicator used to identify general obesity [9]. Waist circumference (WC) can provide information on the distribution of body fat and is strongly correlated with central fat localization [17-19]. Therefore, BMI and WC were used to define general and abdominal obesity in this study, respectively. Since ethnicities and dietary patterns are different in different countries, the prevalence and extent of obesity vary. Previous studies have reported that Asians have higher body fat content than Western people with the same BMI $[20,21]$. Therefore, specific cut-offs of BMI should be used to define overweight and obesity in different countries. In this study, ethnicity-based cutoffs for BMI were used to define overweight and obesity according to the WHO recommendations for Chinese people. Based on the China Health and Nutrition Survey (CHNS), the aims of this study were to investigate the trends in the prevalence of overweight, general obesity, and abdominal obesity as well as the distributions of BMI and WC among the Chinese population. As a result, this study would provide more comprehensive and accurate evidence of the trend and distribution of general and abdominal obesity during the last three decades in China.

\section{Methods}

\section{Study design}

As an ongoing open cohort and international collaborative project between the Carolina Population Center at the University of North Carolina at Chapel Hill and the National Institute for Nutrition and Health (NINH, formerly the National Institute of Nutrition and Food Safety) at the Chinese Center for Disease Control and Prevention (CCDC), the CHNS was designed to examine the effects of the health, nutrition, and family planning policies and programs implemented by national and local governments. Furthermore, how the social and economic transformation of the Chinese society is affecting the health and nutritional status of its population is explored in this survey. Nine provinces varying substantially in geography, economic development, public resources, and health indicators are covered in the CHNS. A multistage, random cluster process was used to obtain the samples in each province. Counties in the nine provinces were stratified by income (low, middle, and high). And a weighted sampling scheme was used to randomly select four counties from each province. In addition, the provincial capital and a lower income city were selected when feasible; however, other large cities rather than provincial capitals had to be selected in two provinces. Villages and townships within the counties and urban/suburban neighborhoods within the cities were selected randomly. The sample is diverse, with variation in a wide-ranging set of socioeconomic factors (income, employment, education, and modernization) and other related health, nutritional, and demographic measures. Because of the long duration and wide geographic coverage, the CHNS can represent the population demographics of China and document the dramatic economic, social, behavioral, and health status changes that have impacted China. The first round of the CHNS was conducted in 1989 , and the survey was subsequently conducted in 1991, 1993, 1997, 2000, 2004, 2006, 2009, and 2011. A detailed description of the survey design and procedures has been published elsewhere [22].

\section{Study population}

Data were obtained from all nine waves of the CHNS conducted from 1989 to 2011. The inclusion criteria was as following: those aged $\geq 18$ years at baseline; those with available data on sex and detailed physical examination (e.g., weight and height). The exclusion criteria was as following: those being pregnant or lactating at the time of survey; and those with missing or implausible outlying data (e.g., weight $>300 \mathrm{~kg}$ or $<20 \mathrm{~kg}, \mathrm{WC}<20 \mathrm{~cm}$ ). 


\section{Measurements and definitions of overweight, general obesity, and abdominal obesity}

Weight, height, and WC were measured by trained healthcare workers following standardized protocols and performed at the same location as well as followed the same protocol at each survey visit. Height was measured to the nearest $0.1 \mathrm{~cm}$ without wearing shoes using a portable stadiometer. Weight was measured to the nearest $0.1 \mathrm{~kg}$ using a calibrated beam scale while wearing lightweight clothing. BMI was calculated as weight (in $\mathrm{kg}$ ) divided by the square of height (in $\mathrm{m}$ ). WC was measured at a point midway between the lowest rib and the iliac crest in a horizontal plane using nonelastic tape.

Since the WHO proposed the additional trigger points to define overweight and obesity for public health action in Asian populations, it was more significant to reflect the trends of overweight and obesity according to the suggestions of the WHO for Chinese population [23]. Therefore, overweight was defined as a $23.0 \mathrm{~kg} / \mathrm{m}^{2} \leq$ $\mathrm{BMI}<27.5 \mathrm{~kg} / \mathrm{m}^{2}$, and general obesity was defined as a $\mathrm{BMI} \geq 27.5 \mathrm{~kg} / \mathrm{m}^{2}$. Abdominal obesity was defined as a $\mathrm{WC} \geq 90 \mathrm{~cm}$ for males and $\geq 80 \mathrm{~cm}$ for females. Grade 1, grade 2, and grade 3 obesity were defined as $27.5 \mathrm{~kg} /$ $\mathrm{m}^{2} \leq \mathrm{BMI}<32.5 \mathrm{~kg} / \mathrm{m}^{2}, \quad 32.5 \mathrm{~kg} / \mathrm{m}^{2} \leq \mathrm{BMI}<37.5 \mathrm{~kg} / \mathrm{m}^{2}$, and $\mathrm{BMI} \geq 37.5 \mathrm{~kg} / \mathrm{m}^{2}$, respectively [23].

\section{Statistical analysis}

Data are reported as the median (interquartile range) for $\mathrm{BMI}$ and $\mathrm{WC}$ and the frequency and percent (95\% confidence interval $(C I)$ ) for overweight, general obesity, grade 1-3 obesity, and abdominal obesity. Since there was clustering for the subjects from the same household, generalized estimated equations were employed to correct the random effect and analyze the linear trends in the prevalence of overweight, general and abdominal obesity $[24,25]$. Analyses were stratified by sex and age, which was defined as $18-39$ years, $40-59$ years, and $\geq 60$ years. Generalized linear mixed models were used to obtain the annual odds ratios (ORs) [26]. In this study, the direct method was used to obtain the age-adjusted prevalence of general and abdominal obesity. The data from the Chinese population census in 2010 were considered as the reference. First, the expected number of individuals with obesity was calculated as the prevalence of obesity in each age- subgroup multiplied by the number from the population censuses in the corresponding age- subgroup. Second, the total expected number of individuals with obesity was calculated as the sum of the expected number of obesity individuals in each age- subgroup. Third, the age-adjusted prevalence of obesity was calculated as the total expected number of obesity individuals divided by the total number of individuals from the population census. Similarly, the age-adjusted prevalence of overweight, grade 1-3 obesity, and abdominal obesity were obtained. All analyses were conducted in SAS 9.4 (SAS Institute Inc., Cary, NC, USA). A twotailed test was used, and the significance level was set at $\alpha=0.05$.

\section{Results}

The characteristics of the nine waves of the CHNS conducted from 1989 to 2011 are presented in Table 1. The sample sizes of the nine waves were 5080 in 1989, 8382 in 1991, 8017 in 1993, 8473 in 1997, 9374 in 2000, 9100 in 2004, 9039 in 2006, 9426 in 2009, and 12,543 in 2011.

The trends in the distributions of BMI and WC from 1989 to 2011 are displayed in Table 2. The median BMI and WC at the follow- up were $23.31 \mathrm{~kg} / \mathrm{m}^{2}$ and $80 \mathrm{~cm}$, respectively. The median $\mathrm{BMI}$ increased significantly from 1989 to 2011 in all subgroups (all $P<0.0001$ ). The median BMI increased by $2.65 \mathrm{~kg} / \mathrm{m}^{2}$ in males and 1.90 $\mathrm{kg} / \mathrm{m}^{2}$ in females. In the stratified analyses by age, there were linear increasing trends in all subgroups (all $P<$ 0.0001 ), with the exception of the 18-39 years group in women, which did not fall within the linearly increasing trend. The trends in WC were similar with those in BMI. The median WC increased by $8.50 \mathrm{~cm}$ in men and $7.00 \mathrm{~cm}$ in women. Significant increases in the median WC were observed in all subgroups (all $P<0.0001$ ).

The prevalence of overweight, general obesity, and abdominal obesity are reported in Table 3 . In total, the age-adjusted prevalence of overweight increased significantly from 23.82 to $38.80 \%(P<0.0001)$. The ageadjusted prevalence of overweight increased significantly from 16.49 to $42.04 \%$ in men $(P<0.0001)$ and from 27.44 to $36.06 \%$ in women $(P<0.0001)$. Moreover, the prevalence of overweight in men (95\% CI: 40.78-43.30\%) was greater than that in women (95\% CI: 34.91-37.22\%) in 2011. In all age groups, significant increases in the prevalence of overweight were observed in both men and women $(P<0.0001)$. Similarly, the age-adjusted prevalence of general obesity increased from 2.15 to $13.99 \%$ in total, from 1.46 to $14.99 \%$ in men, and from 2.78 to $13.22 \%$ in women (all $P<0.0001$ ). There were significant increases in the prevalence of general obesity among all subgroups (all $P<0.0001)$. There were significant increases in the age-adjusted prevalence of abdominal obesity in the total sample (from 19.84 to $43.15 \%$, $P<0.0001$ ), in men (from 9.17 to $34.70 \%, P<0.0001$ ), and in women (from 29.75 to $50.75 \%, P<0.0001$ ). Compared to men, there was a higher prevalence of abdominal obesity among women across all age groups and cycles of surveys.

Table 4 shows the prevalence of overweight, general obesity, and abdominal obesity in different smoking status, marital status, and educational levels. In all subgroups, the prevalence of the three indicators increased significantly, with the exception of overweight in the 
Table 1 The characteristics of CHNS from 1989 to 2011

\begin{tabular}{llllllllll}
\hline Characteristics & 1989 & 1991 & 1993 & 1997 & 2000 & 2004 & 2006 & 2009 & 2011 \\
\hline N & 5080 & 8382 & 8017 & 8473 & 9374 & 9100 & 9039 & 9426 & 12,543 \\
Age & & & & & & & & \\
$\quad 18-39$ & $4206(82.80)$ & $4395(52.43)$ & $3945(49.21)$ & $3689(43.54)$ & $3773(40.25)$ & $2890(31.76)$ & $2555(28.27)$ & $2425(25.73)$ & $2957(23.57)$ \\
$\quad 40-59$ & $866(17.05)$ & $2718(32.43)$ & $2786(34.75)$ & $3245(38.30)$ & $3807(40.61)$ & $4125(45.33)$ & $4221(46.70)$ & $4391(46.58)$ & $5896(47.01)$ \\
$\quad 60-100$ & $8(0.16)$ & $1269(15.14)$ & $1286(16.04)$ & $1539(18.16)$ & $1794(19.14)$ & $2085(22.91)$ & $2263(25.04)$ & $2610(27.69)$ & $3690(29.42)$ \\
Sex & & & & & & & & & \\
$\quad$ Males & $2401(47.26)$ & $4052(48.34)$ & $3867(48.24)$ & $4171(49.23)$ & $4520(48.22)$ & $4348(47.78)$ & $4255(47.07)$ & $4485(47.58)$ & $5890(46.96)$ \\
Females & $2679(52.74)$ & $4330(51.66)$ & $4150(51.76)$ & $4302(50.77)$ & $4854(51.78)$ & $4752(52.22)$ & $4784(52.93)$ & $4941(52.42)$ & $6653(53.04)$ \\
\hline
\end{tabular}

divorced group $(P=0.2193)$. The higher prevalence of overweight, general obesity, and abdominal obesity were found in non- smoking group. The higher prevalence of abdominal obesity was found in the widowed group and the group with a primary education or no degree.

The prevalence of grade 1 , grade 2 , and grade 3 combined obesity are presented in Table 5 . The age-adjusted prevalence of grade 1 obesity increased significantly in the total sample (from 2.08 to $12.01 \%, P<0.0001$ ), in men (from 1.38 to $13.25 \%, P<0.0001$ ), and in women (from 2.74 to $11.03 \%, P<0.0001$ ). In all age groups, the prevalence of grade 1 obesity increased significantly. Similar trends in the age-adjusted prevalence of grade 2 obesity and grade 3 obesity combined were observed in the total sample as well as both men and women. There were significant increases in the prevalence of grade 2 obesity and grade 3 obesity combined in all age groups except the prevalence of grade 2 obesity in the $60-100$ years group ( $P=0.0629$ in men and 0.2130 in women).

The results of the trends in all obesity-related indicators are expressed as annual changes in ORs and displayed in Table 6. For all indicators, there were significant increases in the ORs in the total sample and both men and women (all $P<0.0001$ ). Compared to women, higher ORs in all indicators were observed in men with the exception of grade 2 obesity.

\section{Discussion}

The present study showed that there were significant increases in the age-adjusted prevalence of overweight and general obesity defined by BMI as well as abdominal obesity defined by WC in Chinese adults in the past 22 years. Compared to women, the changes in BMI and WC were particularly pronounced in men. Moreover, the age-adjusted prevalence of overweight in men was greater than that in women. However, the age-adjusted prevalence of abdominal obesity was reversed. Notably, according to the annual ORs, the increases in the prevalence of all indicators in men were greater than those in women, with the exception of grade 2 obesity. The annual ORs of general obesity, abdominal obesity, and grade 1 obesity decreased significantly with age in men.

In this study, dramatic increases in the prevalence of overweight, general obesity, and abdominal obesity were observed among Chinese adults from 1989 to 2011. The increases occurred in almost all studied sex and age groups, which was accordance with the previous studies $[17,27,28]$. Moreover, the increasing trends in all indicators appeared to continue but not slow or level off. If no effective intervention is implemented to control the prevalence of obesity, China will follow in the footsteps of the U.S., which will lead to an obesity crisis [29, 30]. A previous study reported that the Chinese diet was shifting toward a Westernized diet, as characterized by the proliferation of fast food chains since the late 1980s [31]. As a result, the consumption of animal food and edible oil has dramatically increased; in contrast, the intake of cereals and starchy roots has declined [15]. Therefore, the obesity epidemic in China is attributed to the increasing availability of food, the lack of physical activity, and the Westernization of the dietary pattern.

WC is a simple and effective measure of abdominal obesity and has often been shown to be a strong predictor of an increased risk of hypertension, diabetes, dyslipidemia, metabolic syndrome, and coronary heart disease, independent of BMI $[32,33]$. In this study, the age-adjusted prevalence of abdominal obesity defined by WC considerably increased from 1989 to 2011, especially in women, which was in line with the previous study [27]. However, a previous study reported that the distribution of higher WC greatly increased from 1993 to 2009 in men [17]. In 2011, the age-adjusted prevalence of abdominal obesity in women was $50.75 \%$. Note that the prevalence of abdominal obesity in the 40-59 years old and 60-100 years old groups were 61.11 and $68.20 \%$ in 2011 , respectively. Therefore, the high prevalence of abdominal obesity poses a serious public health challenge in China.

According to the annual ORs, there were significant increases in the prevalence of all obesity-related indicators. Compared to women, there were more rapid 


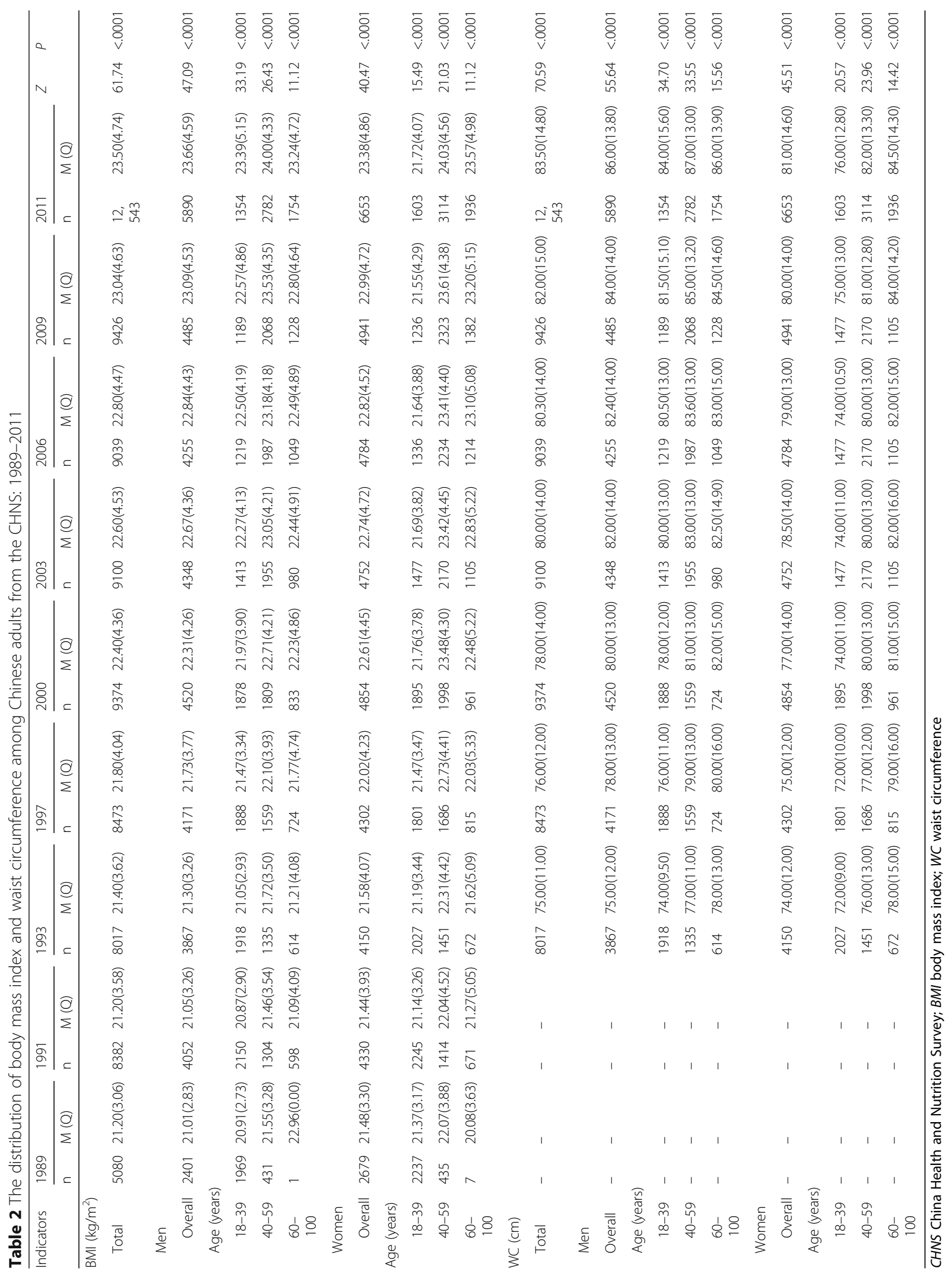




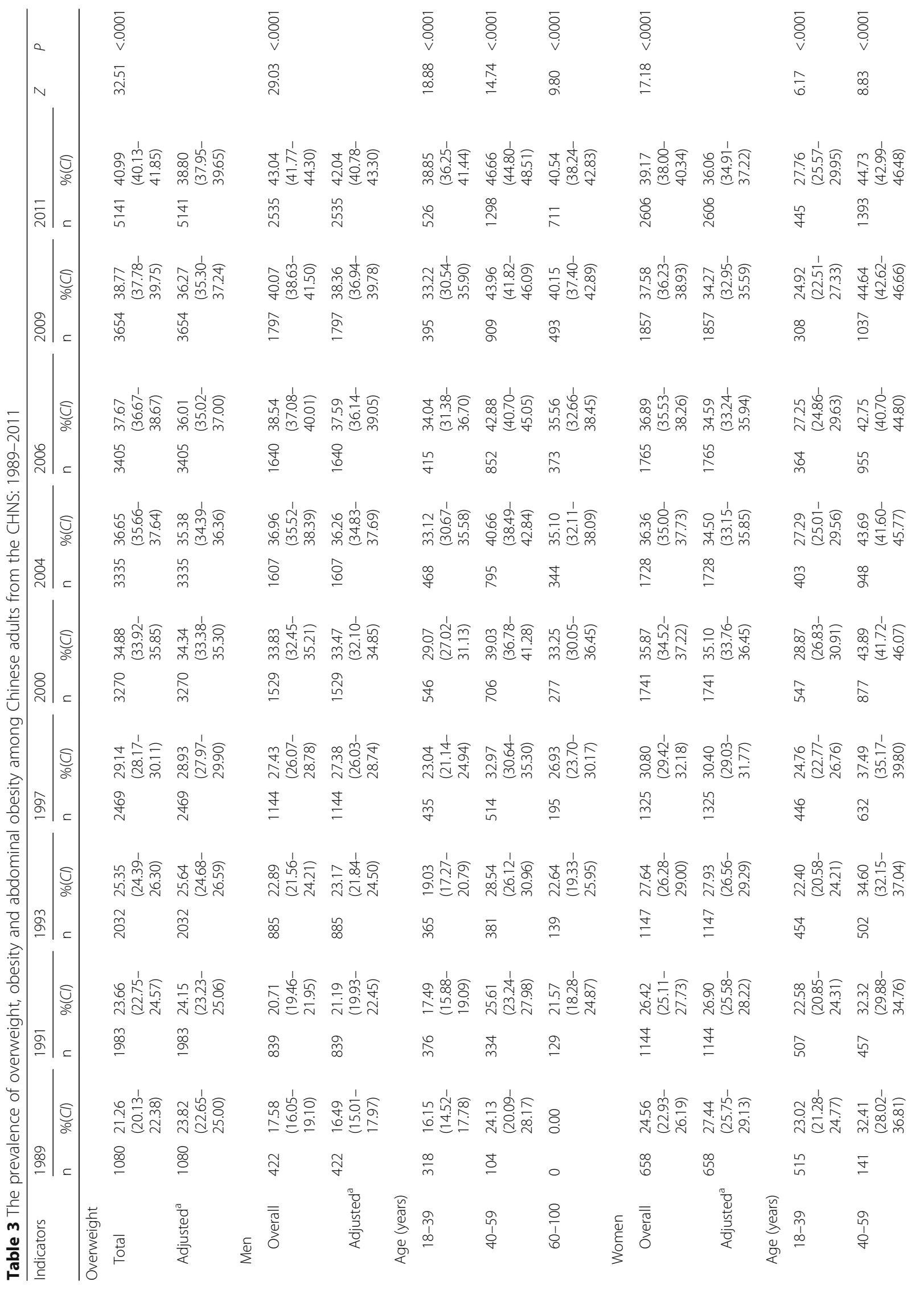




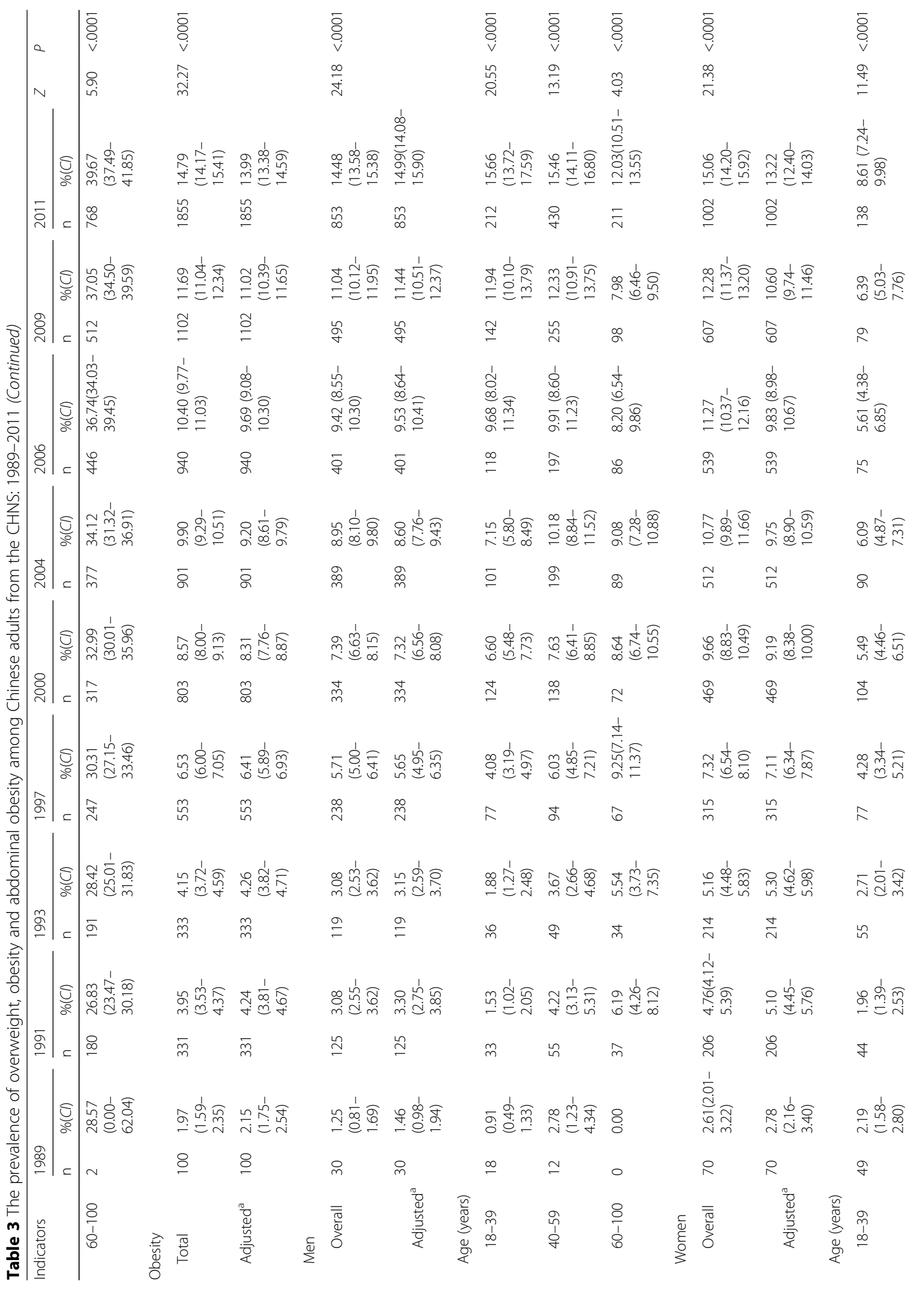




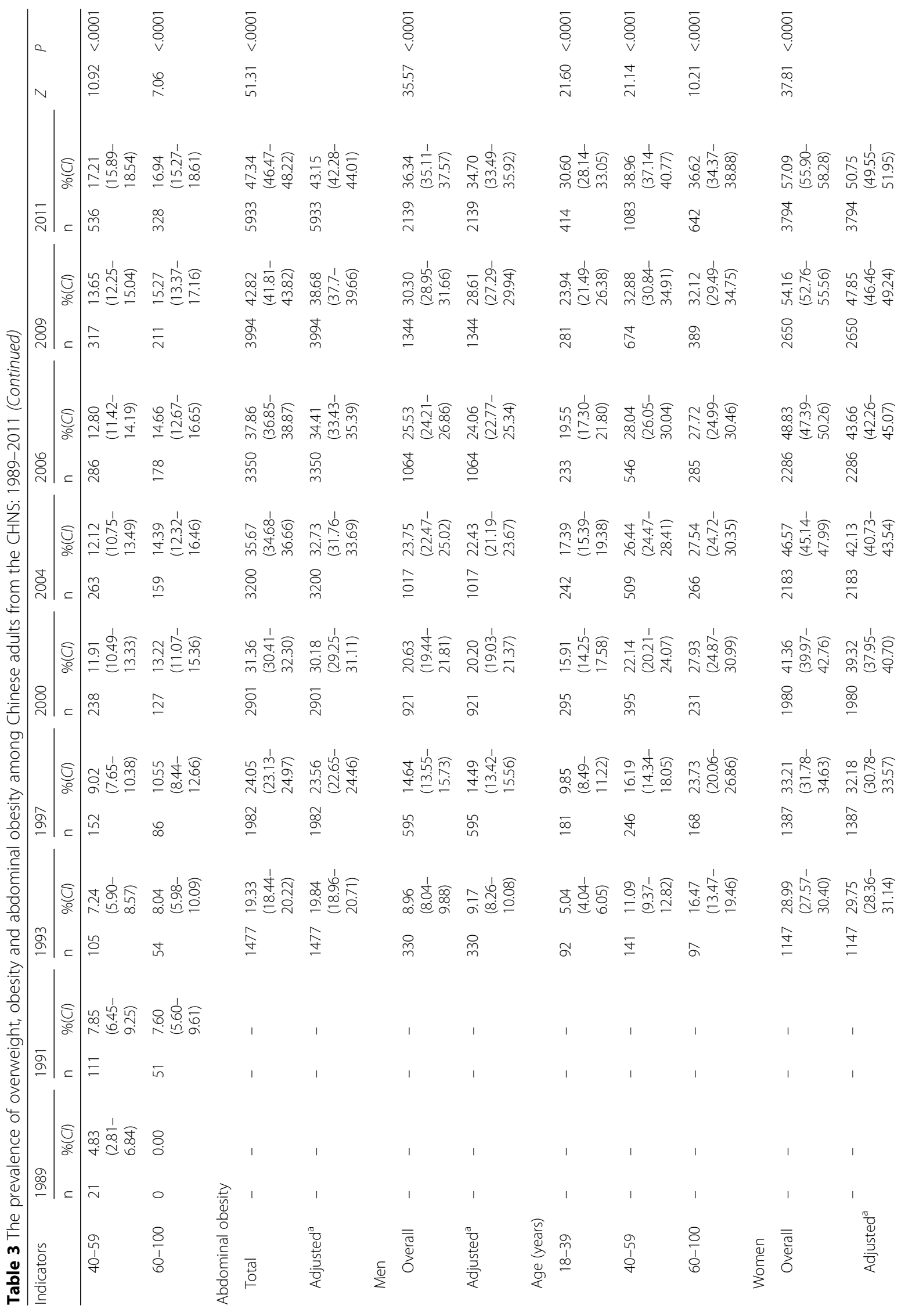




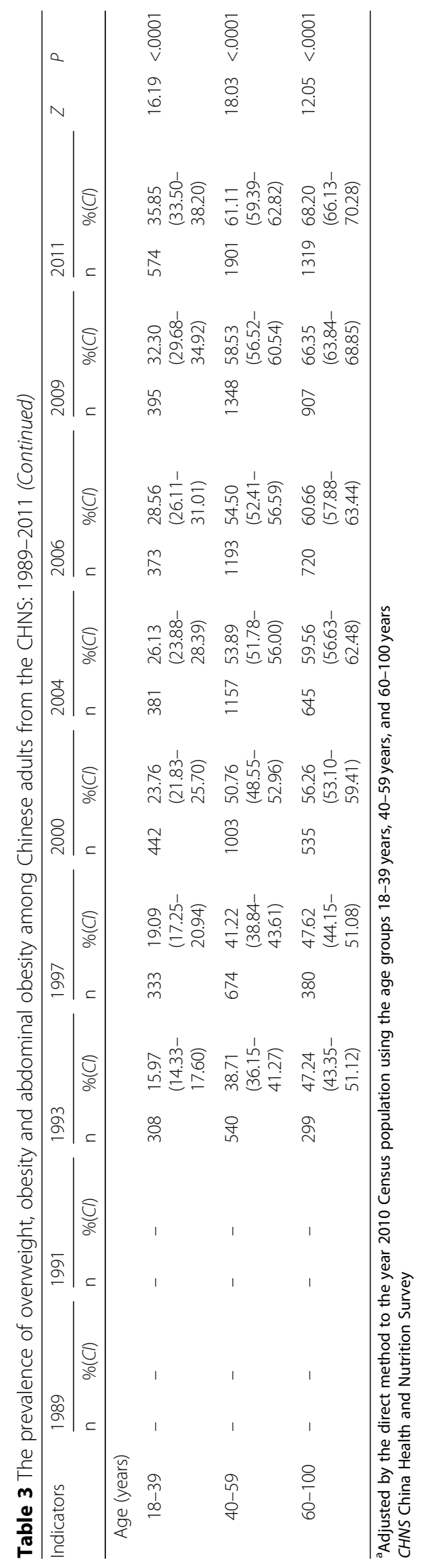




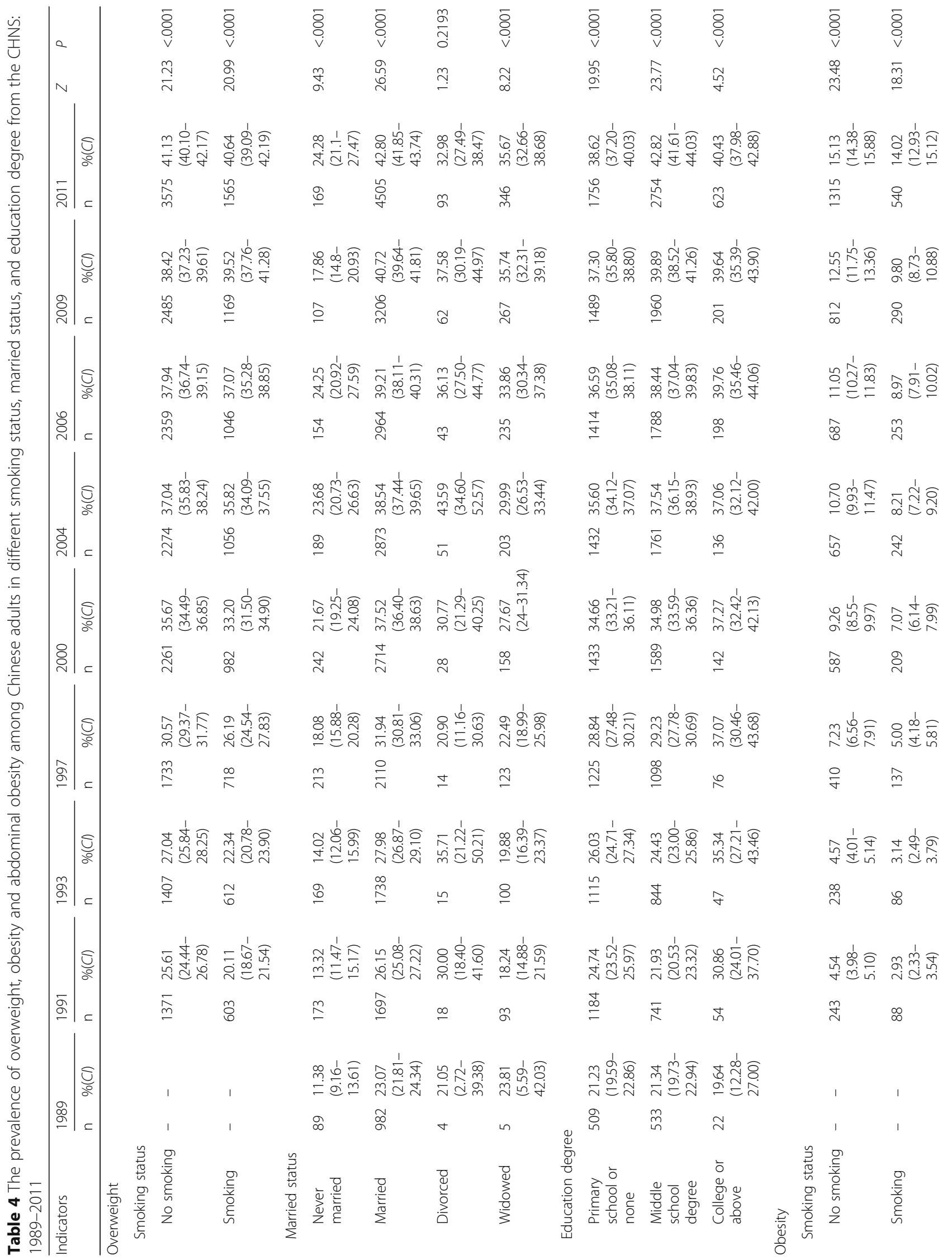




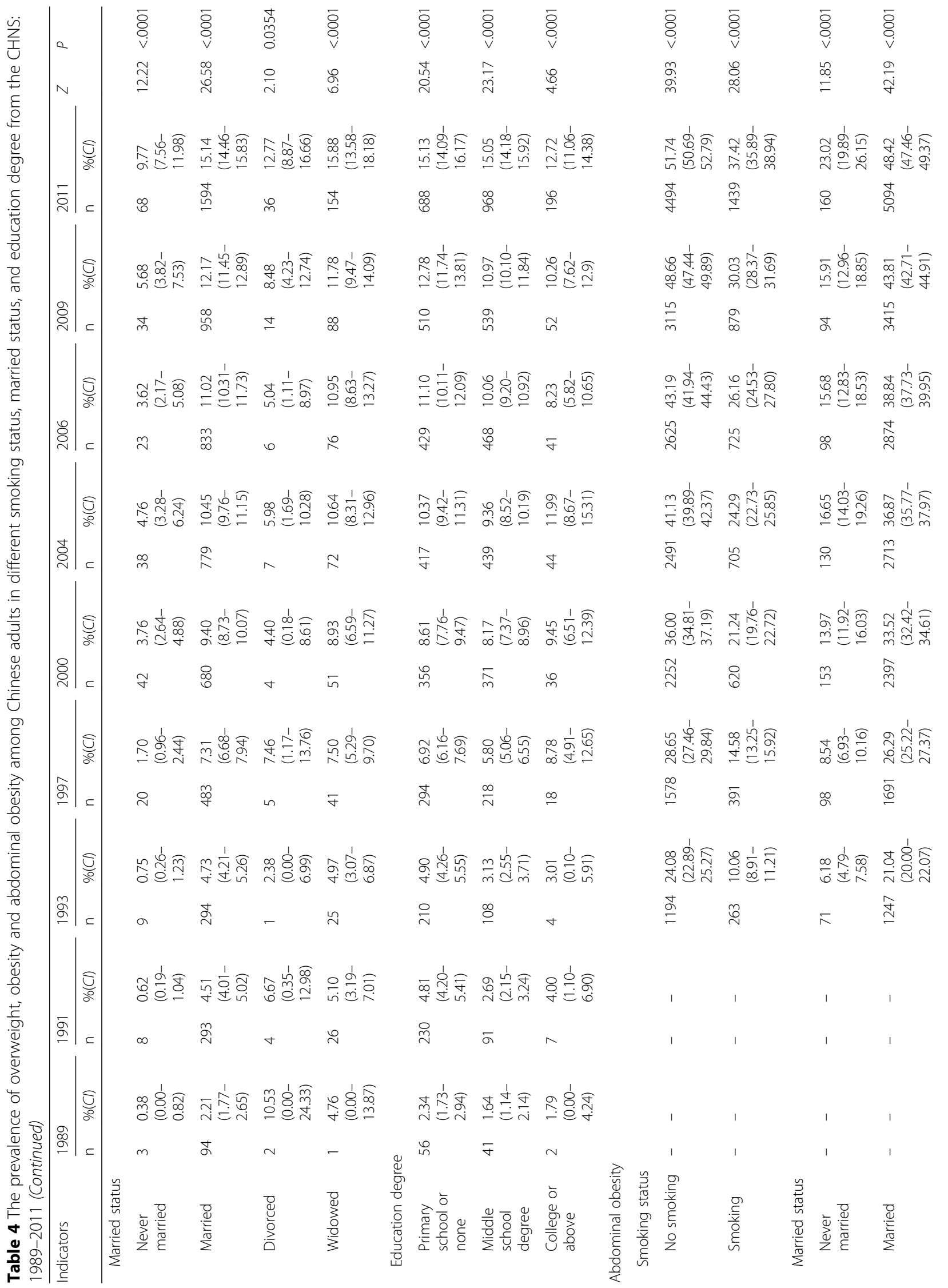




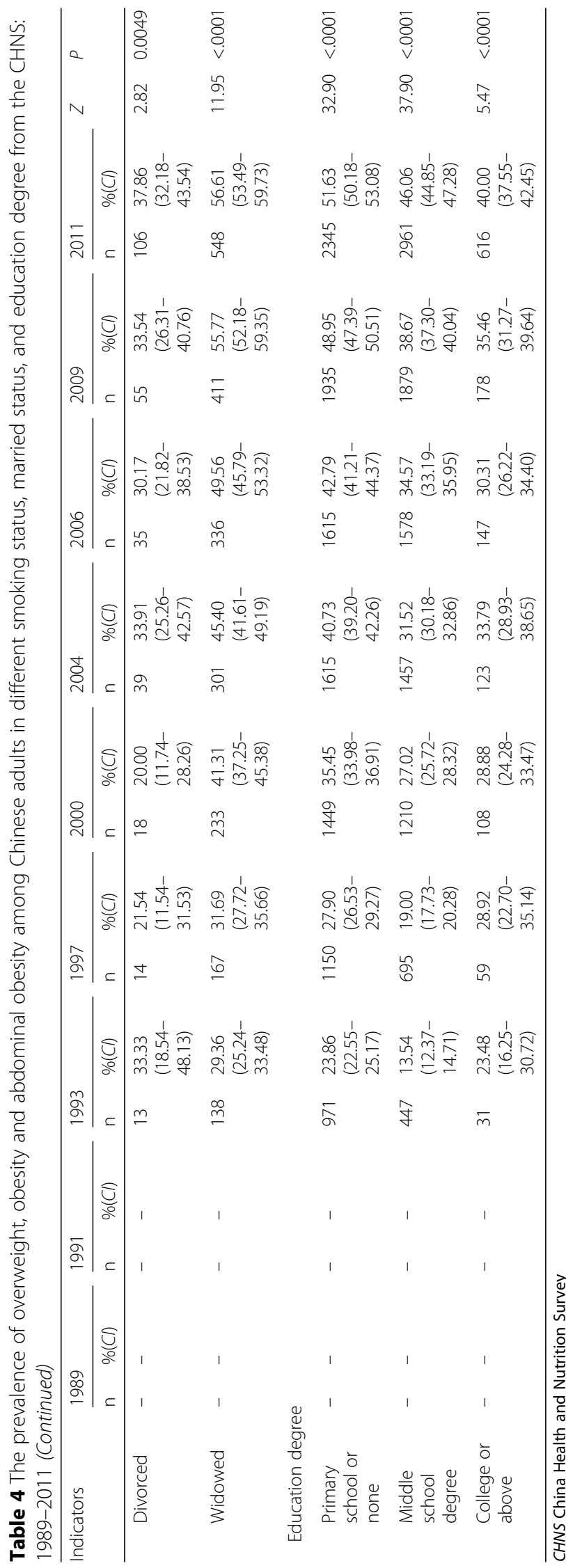




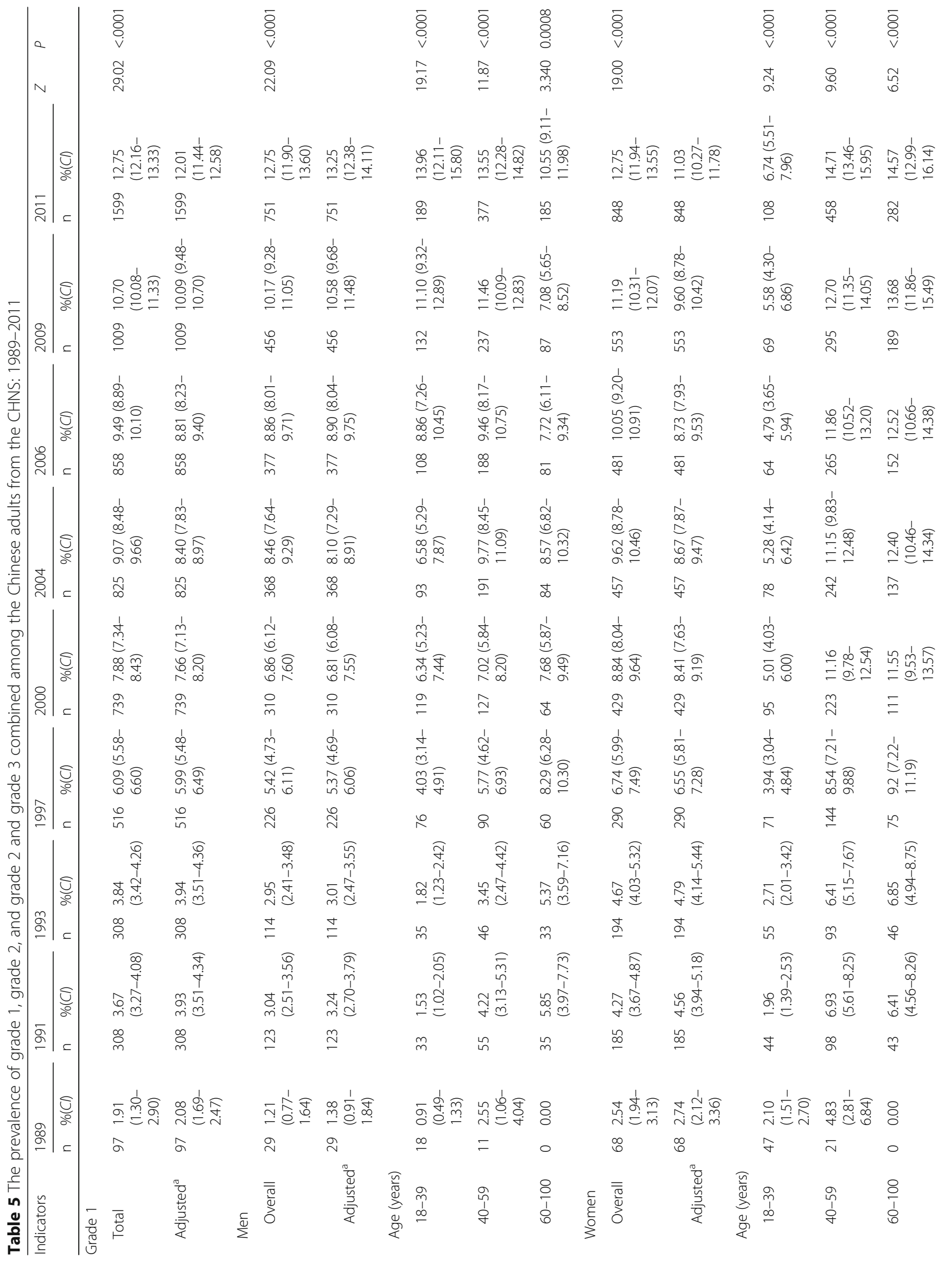




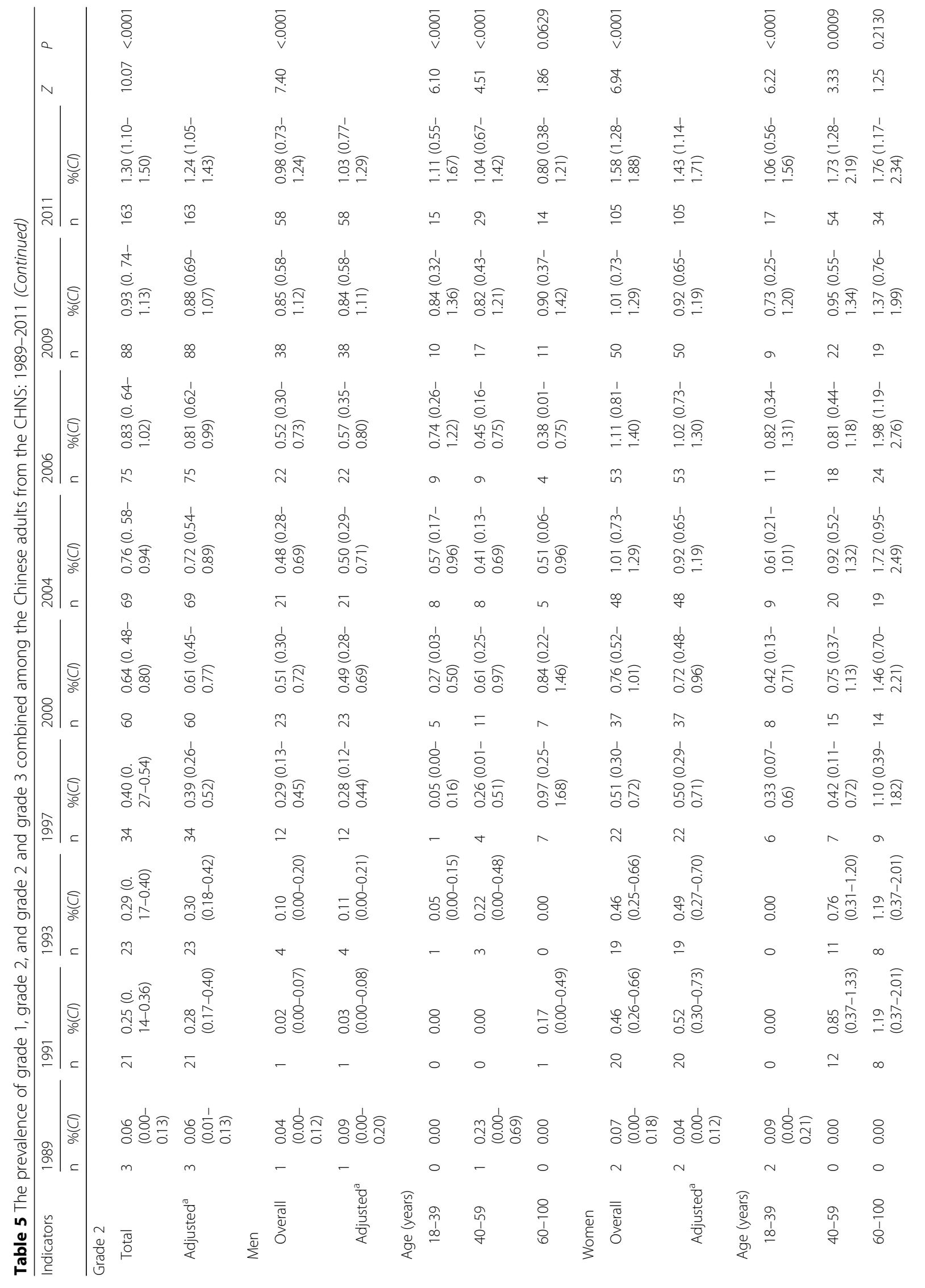




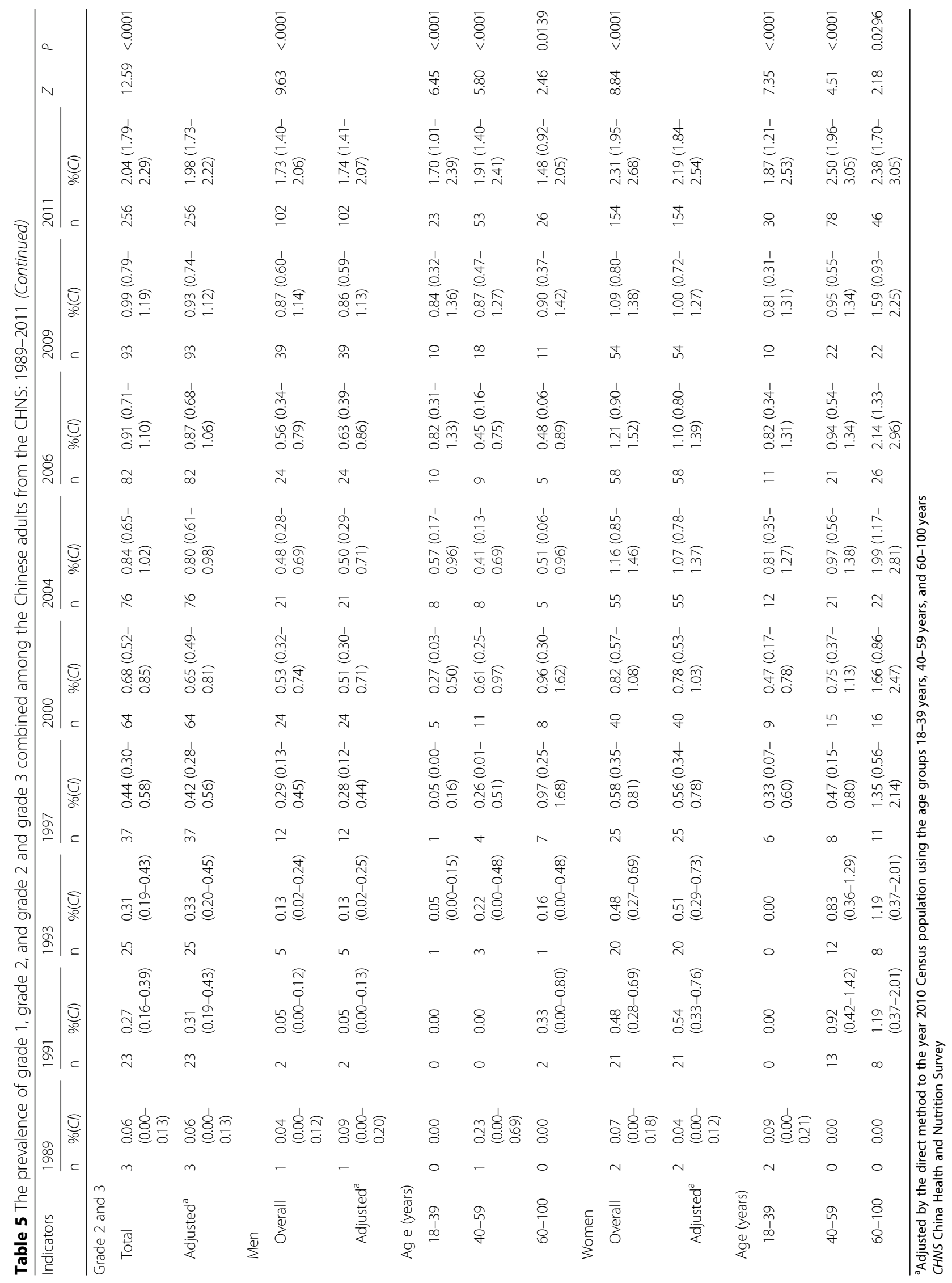


Table 6 Estimated annual increase in the odds of obesity profiles prevalence among the Chinese adults by sex and age from the CHNS: 1989-2011

\begin{tabular}{|c|c|c|c|c|c|c|c|c|c|c|c|c|}
\hline \multirow[t]{2}{*}{ Indicators } & \multicolumn{2}{|l|}{ Overweight } & \multicolumn{2}{|l|}{ Obesity } & \multicolumn{2}{|c|}{ Abdominal obesity } & \multicolumn{2}{|c|}{ Grade 1 obesity } & \multicolumn{2}{|c|}{ Grade 2 obesity } & \multicolumn{2}{|c|}{$\begin{array}{l}\text { Grade } 2 \text { and } 3 \\
\text { combined obesity }\end{array}$} \\
\hline & $O R(95 \% C l)$ & $P$ & $O R(95 \% C l)$ & $P$ & $O R(95 \% C l)$ & $P$ & $O R(95 \% C l)$ & $P$ & $O R(95 \% C l)$ & $P$ & $O R(95 \% C l)$ & $P$ \\
\hline Total & $\begin{array}{l}1.041(1.039- \\
1.043)\end{array}$ & $<.0001$ & $\begin{array}{l}1.074(1.070- \\
1.078)\end{array}$ & $<.0001$ & $\begin{array}{l}1.073(1.070- \\
1.076)\end{array}$ & $<.0001$ & $\begin{array}{l}1.07(1.066- \\
1.074)\end{array}$ & $<.0001$ & $\begin{array}{l}1.087(1.073- \\
1.102)\end{array}$ & $<.0001$ & $\begin{array}{l}1.108(1.094- \\
1.123)\end{array}$ & $<.0001$ \\
\hline \multicolumn{13}{|l|}{ Men } \\
\hline Overall & $\begin{array}{l}1.055(1.052- \\
1.058)\end{array}$ & $<.0001$ & $\begin{array}{l}1.087(1.081- \\
1.093)\end{array}$ & $<.0001$ & $\begin{array}{l}1.089(1.083- \\
1.094)\end{array}$ & $<.0001$ & $\begin{array}{l}1.082(1.075- \\
1.088)\end{array}$ & $<.0001$ & $\begin{array}{l}1.117(1.089- \\
1.147)\end{array}$ & $<.0001$ & $\begin{array}{l}1.148(1.120- \\
1.178)\end{array}$ & $<.0001$ \\
\hline \multicolumn{13}{|l|}{ Age } \\
\hline $18-39$ & $\begin{array}{l}1.056(1.050- \\
1.061)\end{array}$ & $<.0001$ & $\begin{array}{l}1.125(1.113- \\
1.137)\end{array}$ & $<.0001$ & $\begin{array}{l}1.104(1.093- \\
1.114)\end{array}$ & $<.0001$ & $\begin{array}{l}1.118(1.106- \\
1.130)\end{array}$ & $<.0001$ & $\begin{array}{l}1.195(1.133- \\
1.261)\end{array}$ & $<.0001$ & $\begin{array}{l}1.223(1.159- \\
1.290)\end{array}$ & $<.0001$ \\
\hline $40-59$ & $\begin{array}{l}1.045(1.040- \\
1.050)\end{array}$ & $<.0001$ & $\begin{array}{l}1.077(1.068- \\
1.087)\end{array}$ & $<.0001$ & $\begin{array}{l}1.085(1.078- \\
1.093)\end{array}$ & $<.0001$ & $\begin{array}{l}1.072(1.062- \\
1.082)\end{array}$ & $<.0001$ & $\begin{array}{l}1.099(1.056- \\
1.143)\end{array}$ & $<.0001$ & $\begin{array}{l}1.147(1.101- \\
1.194)\end{array}$ & $<.0001$ \\
\hline $\begin{array}{l}60- \\
100\end{array}$ & $\begin{array}{l}1.046(1.038- \\
1.054)\end{array}$ & $<.0001$ & $\begin{array}{l}1.028(1.016- \\
1.041)\end{array}$ & $<.0001$ & $\begin{array}{l}1.048(1.039- \\
1.058)\end{array}$ & $<.0001$ & $\begin{array}{l}1.025(1.011- \\
1.038)\end{array}$ & 0.0002 & $\begin{array}{l}1.045(0.997- \\
1.096)\end{array}$ & 0.0658 & $\begin{array}{l}1.062(1.017- \\
1.109)\end{array}$ & 0.0061 \\
\hline \multicolumn{13}{|l|}{ Women } \\
\hline Overall & $\begin{array}{l}1.030(1.027- \\
1.033)\end{array}$ & $<.0001$ & $\begin{array}{l}1.065(1.060- \\
1.070)\end{array}$ & $<.0001$ & $\begin{array}{l}1.068(1.064- \\
1.072)\end{array}$ & $<.0001$ & $\begin{array}{l}1.061(1.055- \\
1.066)\end{array}$ & $<.0001$ & $\begin{array}{l}1.074(1.056- \\
1.091)\end{array}$ & $<.0001$ & $\begin{array}{l}1.09(1.073- \\
1.107)\end{array}$ & $<.0001$ \\
\hline \multicolumn{13}{|l|}{ Age } \\
\hline $18-39$ & $\begin{array}{l}1.013(1.008- \\
1.018)\end{array}$ & $<.0001$ & $\begin{array}{l}1.065(1.054- \\
1.076)\end{array}$ & $<.0001$ & $\begin{array}{l}1.060(1.052- \\
1.067)\end{array}$ & $<.0001$ & $\begin{array}{l}1.055(1.043- \\
1.066)\end{array}$ & $<.0001$ & $\begin{array}{l}1.136(1.092- \\
1.182)\end{array}$ & $<.0001$ & $\begin{array}{l}1.164(1.120- \\
1.209)\end{array}$ & $<.0001$ \\
\hline $40-59$ & $\begin{array}{l}1.025(1.020- \\
1.029)\end{array}$ & $<.0001$ & $\begin{array}{l}1.047(1.040- \\
1.055)\end{array}$ & $<.0001$ & $\begin{array}{l}1.052(1.046- \\
1.058)\end{array}$ & $<.0001$ & $\begin{array}{l}1.044(1.036- \\
1.052)\end{array}$ & $<.0001$ & $\begin{array}{l}1.052(1.026- \\
1.079)\end{array}$ & $<.0001$ & $\begin{array}{l}1.070(1.045- \\
1.097)\end{array}$ & $<.0001$ \\
\hline $\begin{array}{l}60- \\
100\end{array}$ & $\begin{array}{l}1.028(1.021- \\
1.035)\end{array}$ & $<.0001$ & $\begin{array}{l}1.042(1.032- \\
1.052)\end{array}$ & $<.0001$ & $\begin{array}{l}1.054(1.045- \\
1.062)\end{array}$ & $<.0001$ & $\begin{array}{l}1.042(1.031- \\
1.053)\end{array}$ & $<.0001$ & $\begin{array}{l}1.021(0.994- \\
1.048)\end{array}$ & 0.1354 & $\begin{array}{l}1.032(1.006- \\
1.059)\end{array}$ & 0.0146 \\
\hline
\end{tabular}

CHNS China Health and Nutrition Survey

increases in all indicators except grade 2 obesity in men. There were significant differences in the increasing rates of general obesity, abdominal obesity, and grade 1 obesity across the three age groups in men. And the annual ORs decreased significantly with age. Therefore, the obesity population is trending toward a higher proportion of males and younger individuals in China, which should be examined in a well-designed study in the future.

In this study, it was found that the prevalence of all obesity-related indicators increased more rapidly in men than that in women, which was in line with the findings of previous studies [14, 17, 28, 34]. The sex disparity might be explained by sociocultural, socioeconomic, behavioral, and genetic factors. First, obesogenic environmental changes resulting in high calorie intake might have contributed to male dominance in obesity increases. Furthermore, sex hormone responses to obesogenic environmental changes need to be considered [35]. Second, the dietary and physical activity behavioral differences between men and women might partly explain the sex disparity [16]. Third, body image dissatisfaction is more prevalent in women in China [36, 37]. The Chinese 2005 NYRBS (National Youth Risk Behavior Surveillance) showed that $23.6 \%$ of girls and $9.1 \%$ boys tried to lose weight by restricting their diets [38]. This might explain why the prevalence of obesity increased more slowly in women. The prevalence of abdominal obesity in women was higher than that in men, which might be attributed to hormonal levels. When women experience from menopause, estrogen declines rapidly, and follicle stimulating hormone increases. As a result, the accumulation of visceral fat is exacerbated [39]. Therefore, the prevalence of abdominal obesity would increase more rapidly in women.

\section{The strengths and limitations}

Data were obtained from the nationally representative CHNS. Thus, the findings of this study present the true and dynamic description of obesity-related variables in China. Because of the differences in ethnicities and dietary patterns among different countries, the prevalence and extent of obesity vary. Specific cut-offs of BMI should be used to define overweight and obesity in each country. In this study, according to the WHO recommendations for Chinese people, ethnicity-based cut-offs for BMI were used to define overweight and obesity. Therefore, the results of this study provided accurate and realistic estimations of the prevalence of overweight, general obesity, and abdominal obesity in China. 
However, the limitations of this study should be stated. Since the measurement of WC in the CHNS began in 1993, the prevalence of abdominal obesity and the distribution of WC were not reported in 1989 or 1991. The study population focused on children and adults aged $\leq 45$ years old in 1989 , which led to no result presented in the $60-100$ years old group.

\section{Conclusions}

The prevalence of overweight, general obesity, and abdominal obesity increased significantly among Chinese adults from 1989 to 2011. The median BMI and WC increased rapidly over the 22 years. The annual ORs indicated that the increases in the prevalence of overweight, general obesity, and abdominal obesity in men were more rapid than those in women. Therefore, the obesity population is trending toward a higher proportion of males and younger individuals in China.

\section{Abbreviations}

BMI: Body mass index; CCDC: Center for Disease Control and Prevention; CHNS: China Health Nutrition Survey; Cl: Confident interval; NYRBS: National Youth Risk Behavior Surveillance; ORs: Odds ratios; WC: Waist circumference

\section{Acknowledgements}

This research uses data from China Health and Nutrition Survey (CHNS). We thank the National Institute of Nutrition and Food Safety, China Center for Disease Control and Prevention, Carolina Population Center, the University of North Carolina at Chapel Hill, the NIH (R01-HD30880, DK056350, and R01HD38700) and the Fogarty International Center, NIH for financial support for the CHNS data collection and analysis files from 1989 to 2006 and both parties plus the China-Japan Friendship Hospital, Ministry of Health for support for CHNS 2009 and future surveys.

\section{Authors' contributions}

YC wrote the draft paper, QP revised the manuscript and improved the language, $Y Y$ and $S Z$ analyzed the data, YW interpreted the results, and $\mathrm{WL}$ designed the study. All authors have approved the final article.

\section{Funding}

This work was supported by the National Natural Science Foundation of China (71704131). The funding body did not play any roles in the design of the study and collection, analysis, and interpretation of data and in writing the manuscript.

\section{Availability of data and materials}

The datasets generated and/or analyzed during the current study are available in the web: https://www.cpc.unc.edu/projects/china.

\section{Ethics approval and consent to participate}

This study was approved by the IRB of the National Institute for Nutrition and Food Safety, China Center for Disease Control and Prevention, and University of North Carolina at Chapel Hill. Written informed consent was obtained from all subjects.

\section{Consent for publication}

Not applicable.

\section{Competing interests}

The authors declare that they have no competing interests.
Received: 27 January 2019 Accepted: 16 September 2019

Published online: 15 October 2019

\section{References}

1. WHO. The Asia-Pacific perspective: redefining obesity and its treatment. Sydney: Health Communications Australia; 2000.

2. Tian $\mathrm{H}$, Xie $\mathrm{H}$, Song $\mathrm{G}$, Zhang $\mathrm{H}, \mathrm{Hu}$ G. Prevalence of overweight and obesity among 2.6 million rural Chinese adults. Prev Med. 2009;48(1):59-63.

3. Aune D, Sen A, Prasad M, Norat T, Janszky I, Tonstad S, et al. BMI and all cause mortality: systematic review and non-linear dose-response metaanalysis of 230 cohort studies with 3.74 million deaths among 30.3 million participants. Bmj. 2016;353:i2156.

4. Wang Z. Age-dependent decline of association between obesity and mortality: a systematic review and meta-analysis. Obes Res Clin Pract. 2015; $9(1): 1-11$.

5. Flegal KM, Kit BK, Orpana H, Graubard BI. Association of all-cause mortality with overweight and obesity using standard body mass index categories: a systematic review and meta-analysis. JAMA. 2013;309(1):71-82.

6. Tahergorabi Z, Khazaei M, Moodi M, Chamani E. From obesity to cancer: a review on proposed mechanisms. Cell Biochem Funct. 2016:34(8):533-45.

7. Li Y-C, Li C-L, Qi J-Y, Huang L-N, Shi D, Du S-S, et al. Relationships of dietary histidine and obesity in northern chinese adults, an internet-based crosssectional study. Nutrients. 2016;8(7):420.

8. Ogden $\mathrm{CL}$, Carroll MD, Kit BK, Flegal KM. Prevalence of obesity in the United States, 2009-2010. Hyattsville: US Department of Health and Human Services, Centers for Disease Control and Prevention, National Center for Health Statistics; 2012

9. Hou X, Liu Y, Lu H, Ma X, Hu C, Bao Y, et al. Ten-year changes in the prevalence of overweight, obesity and central obesity among the Chinese adults in urban Shanghai, 1998-2007-comparison of two cross-sectional surveys. BMC Public Health. 2013;13(1):1064.

10. Wang Y, Mi J, Shan X, Wang QJ, Ge K. Is China facing an obesity epidemic and the consequences? The trends in obesity and chronic disease in China. Int J Obes. 2007;31(1):177-88.

11. Wu Y. Overweight and obesity in China. Bmj. 2006;333(7564):362-3.

12. Verma S, Hussain ME. Obesity and diabetes: an update. Diabetes Metab Syndr. 2017;11(1):73-9.

13. Popkin BM, Horton S, Kim S, Mahal A, Shuigao J. Trends in diet, nutritional status, and diet-related noncommunicable diseases in China and India: the economic costs of the nutrition transition. Nutr Rev. 2001;59(12):379-90.

14. Wang H, Du S, Zhai F, Popkin BM. Trends in the distribution of body mass index among Chinese adults, aged 20-45 years (1989-2000). Int J Obes. 2007;31(2):272-8

15. Zhai F, Wang H, Du S, He Y, Wang Z, Ge K, et al. Prospective study on nutrition transition in China. Nutr Rev. 2009;67(Suppl 1):S56-61.

16. Bonnefond C, Clément M. Social class and body weight among Chinese urban adults: the role of the middle classes in the nutrition transition. Soc Sci Med. 2014;112:22-9.

17. Xi B, Liang $Y$, He T, Reilly KH, Hu Y, Wang Q, et al. Secular trends in the prevalence of general and abdominal obesity among Chinese adults, 19932009. Obes Rev. 2012;13(3):287-96.

18. Du T, Sun $X$, Yin P, Huo R, Ni C, Yu X. Increasing trends in central obesity among Chinese adults with normal body mass index, 1993-2009. BMC Public Health. 2013:13(1):327.

19. Niu J, Seo D-C. Central obesity and hypertension in Chinese adults: a 12year longitudinal examination. Prev Med. 2014:62:113-8.

20. Deurenberg P, Yap M, van Staveren WA. Body mass index and percent body fat: a meta analysis among different ethnic groups. Int J Obes Relat Metab Disord. 1998;22(12):1164-71.

21. Chang CJ, Wu CH, Chang CS, Yao WJ, Yang YC, Wu JS, et al. Low body mass index but high percent body fat in Taiwanese subjects: implications of obesity cutoffs. Int J Obes Relat Metab Disord. 2003;27(2):253-9.

22. Popkin BM, Du S, Zhai F, Zhang B. Cohort profile: the China health and nutrition survey - monitoring and understanding socio-economic and health change in China, 1989-2011. Int J Epidemiol. 2010;39(6):1435-40.

23. Expert Consultation WHO. Appropriate body-mass index for Asian populations and its implications for policy and intervention strategies. Lancet. 2004;363(9403):157-63.

24. Lipsitz SR, Fitzmaurice GM, Orav EJ, Laird NM. Performance of generalized estimating equations in practical situations. Biometrics. 1994;50(1):270-8. 
25. Hardin JW, Hilbe JM. Generalized estimating equations: chapman and hall/ CRC; 2012.

26. Breslow NE, Clayton DG. Approximate inference in generalized linear mixed models. J Am Stat Assoc. 1993;88(421):9-25.

27. Gordon-Larsen P, Wang H, Popkin BM. Overweight dynamics in Chinese children and adults. Obes Rev. 2014;15(Suppl 1):37-48.

28. Mi Y-J, Zhang B, Wang H-J, Yan J, Han W, Zhao J, et al. Prevalence and secular trends in obesity among Chinese adults, 1991-2011. Am J Prev Med. 2015;49(5):661-9.

29. Flegal KM, Carroll MD, Kit BK, Ogden CL. Prevalence of obesity and trends in the distribution of body mass index among US adults, 1999-2010. JAMA. 2012;307(5):491-7.

30. Ogden CL, Carroll MD, Curtin LR, McDowell MA, Tabak CJ, Flegal KM. Prevalence of overweight and obesity in the United States, 1999-2004. JAMA. 2006:295(13):1549-55.

31. Popkin BM. The nutrition transition in the developing world. Dev Pol Rev. 2003;21(5-6):581-97.

32. Wang Y, Rimm EB, Stampfer MJ, Willett WC, Hu FB. Comparison of abdominal adiposity and overall obesity in predicting risk of type 2 diabetes among men. Am J Clin Nutr. 2005;81(3):555-63.

33. Pouliot M-C, Després J-P, Lemieux S, Moorjani S, Bouchard C, Tremblay A, et al. Waist circumference and abdominal sagittal diameter: best simple anthropometric indexes of abdominal visceral adipose tissue accumulation and related cardiovascular risk in men and women. Am J Cardiol. 1994;73(7):460-8.

34. Wildman RP, Gu D, Muntner P, Wu X, Reynolds K, Duan X, et al. Trends in overweight and obesity in Chinese adults: between 1991 and 1999-2000. Obesity. 2008;16(6):1448-53.

35. Yoo S, Cho H-J, Khang Y-H. General and abdominal obesity in South Korea, 1998-2007: gender and socioeconomic differences. Prev Med. 2010;51(6): 460-5.

36. Brennan MA, Lalonde CE, Bain JL. Body image perceptions: do gender differences exist. Psi Chi J Undergraduate Res. 2010;15(3):130-8.

37. B Luo, Y Gao, L Ye, L Zhou, W Peng. The Study of the Actuality of Teenagers' Depression of Body Image. Psychological Development and Education. 2005; (4):89-93

38. National Bureau of Statistics of China (2011).China's Statistical Yearbook 2011.

39. Liu P, Ji Y, Yuen T, Rendina-Ruedy E, DeMambro VE, Dhawan S, et al. Blocking FSH induces thermogenic adipose tissue and reduces body fat Nature. 2017;546(7656):107-12.

\section{Publisher's Note}

Springer Nature remains neutral with regard to jurisdictional claims in published maps and institutional affiliations.

Ready to submit your research? Choose BMC and benefit from:

- fast, convenient online submission

- thorough peer review by experienced researchers in your field

- rapid publication on acceptance

- support for research data, including large and complex data types

- gold Open Access which fosters wider collaboration and increased citations

- maximum visibility for your research: over $100 \mathrm{M}$ website views per year

At $\mathrm{BMC}$, research is always in progress.

Learn more biomedcentral.com/submissions 